\title{
UMA ANÁLISE SOBRE A TRANSIÇÃo DA DITADURA MILITAR PARA A DEMOCRACIA NO CHILE
}

\section{AN ANALYSIS ABOUT THE TRANSITION FROM THE MILITARY DICTATORSHIP TO DEMOCRACY IN CHILE}

\author{
${ }^{1}$ Ana Maria D’Ávila Lopes \\ ${ }^{2}$ Isabelle Maria Campos Vasconcelos Chehab
}

\section{RESUMO}

O presente trabalho tem por intuito analisar os meandros da transição entre a ditadura militar e a democracia no Chile. Para tanto, utilizou-se de pesquisa bibliográfica e documental. Inicialmente, discorreu-se sobre os antecedentes históricos chilenos, sublinhando-se a sua constituição como Estado, os traços emblemáticos de sua sociedade civil e de sua corporação militar e a urdidura de seu ordenamento jurídico autoritário. Na sequência, expôs-se sobre a ditadura militar chilena, não se olvidando de comentar sobre a colaboração do governo brasileiro para o golpe ali deflagrado contra o presidente Salvador Allende; a ampla jurisdição dos seus tribunais militares de tempo de guerra em relação aos supostos crimes praticados por opositores do regime, aliada aos seus diminutos índices de absolvição; e o papel desempenhado pelo regime ditatorial chileno para a arregimentação e implementação da Operação Condor. Posteriormente, foram apresentadas as fases e as notas caracterizadoras da transição para a democracia no Chile. Ao final, concluiu-se acerca das similitudes entre o regime ditatorial chileno e o brasileiro. Por semelhante modo, verificou-se da importância do arcabouço normativo autoritário chileno, constituído ainda durante os governos civis, mas fundamental para a intervenção repressiva das forças armadas. Ainda, observou-se da relevância da ditadura chilena para o funcionamento da Operação Condor. Por derradeiro, averiguou-se que a transição chilena foi marcada, principalmente, pela instalação de três sucessivas comissões com o fito de apurar as graves violações de direitos humanos cometidas durante a ditadura chilena; pela intervenção internacional, a exemplo do pedido de extradição e consequente prisão contra Augusto Pinochet; assim como por reiterados pedidos de desculpas institucionais protagonizados pelo Poder Executivo, pelo Poder Judiciário e, mais recentemente, pelas Forças Armadas chilenas.

Palavras-chave: Ditadura chilena, Justiça de transição, Democracia, Operação condor

\footnotetext{
${ }^{1}$ Professora da Universidade de Fortaleza (UNIFOR), Ceará (Brasil). Doutorado em Direito pela Universidade Federal de Minas Gerais (UFMG), Minas Gerais (Brasil) E-mail: anadavilalopes@yahoo.com.br

${ }^{2}$ Doutorado em Direito Constitucional pela Universidade de Fortaleza (UNIFOR), Ceará (Brasil) E-mail: ivchehab@ gmail.com
} 


\begin{abstract}
This study intends to examine the meanders between the military dictatorship and the transition to democracy in Chile. Therefore, it was used bibliographical and documentary research. Initially, it discussed about the Chilean historical background, emphasizing its constitution as a nation, the emblematic traces of its civil society and its military establishment and the warp of its authoritarian legal system. Afterwards, it was exposed about the Chilean military dictatorship, not forgetting to comment the collaboration of the Brazilian government for the coup that triggered against President Salvador Allende; the wide jurisdiction of the military courts in wartime to alleged crimes committed by regime opponents and their tiny levels of absolution and the role played by the Chilean dictatorship for regimentation and implementation of Condor Operation. Then, they were presented the phases and the characterizing notes of transition to democracy in Chile. By the end, it was concluded about the similarities between the Chilean dictatorship and the Brazilian. In the same way, it was notice the importance of the Chilean authoritarian normative framework to the repressive intervention of the armed forces. Still, there was stressed the relevance of the Chilean dictatorship for the functioning of Condor Operation. Finally, it was established that the Chilean transition was mainly marked by the installation of three successive commissions with the aim of investigating serious human rights violations committed during the Chilean dictatorship; the international intervention, such as the request for extradition and subsequent arrest of Augusto Pinochet; as well as by the repeated requests for institutional excuses perpetrated by the Executive, the Judiciary and, more recently, by the Chilean military.
\end{abstract}

Keywords: Chilean dictatorship, Transitional justice, Democracy, Condor operation 


\section{INTRODUÇÃO}

Diferentemente dos demais países do Cone $\mathrm{Sul}^{1}$, o Chile, enquanto nação, sempre foi reconhecimento por sua ode à legalidade e pelo seu respeito às instituições. Já as suas corporações militares, historicamente, notabilizaram-se pela rigidez institucional, pela segregação para com as questões políticas dos civis, assim como pelo seu cumprimento aos ditames legais. A despeito dessa longa tradição, a partir de 1920, observou-se uma mudança de cunho ideológico na sociedade chilena, representada, principalmente, pela imigração europeia, pelas discussões em torno dos direitos sociais trabalhistas e pela crença dos militares enquanto bastiões nacionais, fatores que, quando conjugados, ensejarão a primeira intervenção dos militares no poder central, em 1927; o tensionamento ideológico nas relações entre os civis vinculados à esquerda e os militares; a construção de um arcabouço normativo autoritário nas décadas seguintes; e a deflagração de um golpe militar, em 1973, contra o presidente eleito Salvador Allende, que haveria de perdurar até 1990 e influenciar os modos de exercício do poder e as futuras gerações chilenas.

Destarte, escreveu-se este artigo com o objetivo geral de analisar os meandros entre a ditadura civil chilena e a sua transição para a democracia. Sem olvidar-se de discorrer sobre os antecedentes históricos chilenos; as vinculações entre a ditadura chilena e brasileira e o papel desempenhado pela ditadura chilena para a arregimentação e o funcionamento da Operação Condor.

No que tange à metodologia, elucida-se que a pesquisa realizada teve caráter eminentemente bibliográfico, na medida em que predominantemente se recorreu à leitura e à análise da doutrina nacional e estrangeira. Registra-se também o seu cunho documental, por ter sido utilizada legislação estrangeira. De igual modo, deve ser entendida como pesquisa aplicada, considerando o seu objetivo de colaborar, por meio dos dados aqui reunidos, para a construção de um futuro pacífico. Ademais, trata-se de

\footnotetext{
${ }^{1}$ A título de exemplificação, na Argentina, os militares estiveram à frente do governo nos períodos de1930-1932, 1943-1946, 1955-1958 e 1966-1973. (PEREIRA, 2010, p.83) O Brasil, por seu turno, submeteu-se a diversas intervenções militares (CARVALHO, 2003, p. 112). Mais recentemente, merece destaque a ditadura civil-militar deflagrada em 31 de março de 1964, que perdurou até 1985 .
} 
ensaio eminentemente qualitativo, dada a sua perspectiva de buscar compreender o contexto do objeto investigado.

Nesse contexto, discorreu-se, no primeiro tópico, sobre os antecedentes históricos chilenos, sublinhando-se a sua constituição como Estado, os traços emblemáticos de sua sociedade civil e de sua corporação militar e a urdidura de seu ordenamento jurídico autoritário. Posteriormente, no segundo tópico, expôs-se sobre a ditadura militar chilena, não se olvidando de comentar sobre a colaboração do governo brasileiro para o golpe ali deflagrado contra o presidente Salvador Allende; a ampla jurisdição dos seus tribunais militares de tempo de guerra nos supostos crimes praticados por opositores do regime e nos seus diminutos índices de absolvição; e o papel desempenhado pelo regime ditatorial chileno para a arregimentação e a implementação da Operação Condor. Já no terceiro, foram apresentadas as fases e as notas caracterizadoras da transição para a democracia no Chile.

Ao final, concluiu-se acerca das similitudes entre o regime ditatorial chileno e o brasileiro. Por semelhante modo, verificou-se da importância do arcabouço normativo autoritário chileno, constituído ainda durante os governos civis, mas fundamental para a intervenção repressiva das forças armadas. Ainda, observou-se da relevância da ditadura chilena para o funcionamento da Operação Condor. Por derradeiro, averiguou-se que a transição para a democracia no Chile foi marcada, principalmente, pela instalação de três sucessivas comissões com o fito de apurar as graves violações de direitos humanos cometidas durante a ditadura militar; pela intervenção internacional, a exemplo do pedido de extradição e consequente prisão contra Augusto Pinochet; assim como por reiterados pedidos de desculpas institucionais protagonizados pelo Poder Executivo, pelo Poder Judiciário e, mais recentemente, pelas Forças Armadas chilenas, conforme adiante será explicitado.

\section{ANTECEDENTES HISTÓRICOS}

Durante quase 300 anos, o Chile viveu sob a égide dos espanhóis. Sua independência foi conquistada somente em 1818. Ao longo do século XIX, o Chile 
obteve, também, outras duas importantes conquistas, quais sejam: a região do Atacama, originária do Peru; e uma nova saída para o mar, anteriormente pertencente ao território boliviano. A primeira lhe garantiu o cobre, como sua grande riqueza e elemento principal para sustentação econômica; já a segunda, permitiu-lhe a extensão do seu comércio marítimo.

O Chile constituiu-se, assim, como um país dotado de significativos potenciais econômicos, especialmente em razão de suas minas de cobre. Formou-se por uma população, razoavelmente, miscigenada, mas deveras oligárquica e estratificada socialmente. Enquanto nação esteve vinculada historicamente pelo zelo à burocracia ${ }^{2}$ (PASCUAL, 2004, p.24) e pela obediência ao ordenamento jurídico. (ALMEIDA, 2007, p. 200). Sua primeira constituição data de 1832, substituída pela de 1925 , vigente quando do golpe militar contra o presidente Salvador Allende, em 11 de setembro de 1973.

Por seu turno, o Exército e a Armada chilenos foram criados no início do século XIX, durante as lutas por independência. Tornaram-se conhecidos como corporações pautadas pela rigidez, marcadas pela segregação para com as questões políticas dos civis, assim como pelo seu cumprimento aos ditames legais.

Convém sublinhar que seu rigor e sua apartação para com os civis não foram obra do acaso, mas atributos cuidadosamente forjados, sobretudo, em razão de um convívio sistemático, durante o período de 1885 a 1931, entre o Exército chileno e as tropas alemãs, o que lhes legou o apreço pela autonomia e pela segregação dos militares. (PEREIRA, 2010, p.92).

O zelo pela legalidade perdurou, como traço emblemático da corporação militar, principalmente, até a década de 1920, quando essa tradição foi se degenerando por meio de duas frentes distintas. ${ }^{3}$

2 Característica assemelhada ao Brasil, que foi forjado pela - e na - vinculação com a burocracia. (O’DONNEL, 1987, p. 21-22)

${ }^{3}$ É importante salientar que, conforme explicitou Moraes (2001, p. 236), anteriormente, houve um episódio pontual contra a legalidade envolvendo militares, que, em conjunto com os adversários políticos do então presidente José Manuel Balmaceda (1886-1891), impôs-lhe uma derrota na guerra civil de 1891 e, em seguida, sua retirada do governo. 
A primeira frente pode ser caracterizada pela crescente preocupação dos militares para com a imigração européia e para com as mobilizações populares em prol dos direitos trabalhistas. A apreensão militar residia particularmente na ideia de que os imigrantes europeus, embora em pequeno número, poderiam insuflar os protestos trabalhistas, tornando-se, assim, partes e agentes colaboradores das dificuldades econômicas, e agora políticas, enfrentadas pelo Chile.

Já a segunda frente, que pode ser entendida, inclusive, como conseqüência da primeira, diz respeito à formulação de uma ideologia majoritária dentro da corporação militar de que as forças armadas seriam o último bastião responsável pela "salvação da nação chilena". (ROLLEMBERG; QUADRAT, 2010, p. 549). Com este fundamento, as forças armadas passaram a se imiscuir diretamente nas discussões políticas, inclusive, usurpando, em algumas circunstâncias, as atribuições civis, sob a alegação de sua imprescindibilidade para a pacificação e a redenção do Chile. (PEREIRA, 2010, p. 93).

Em termos fáticos, a primeira intervenção significativa dos militares nas questões políticas civis data de 1927, com a ascensão de Carlos Ibáñez del Campo ao poder central. Ibáñez tornou-se conhecido por seu discurso de caráter populista e em defesa do Estado chileno. Notabilizou-se, também, por ter sido o responsável pela transferência da "força policial centralizada, os carabineros, do Ministério do Interior para o Ministério do Exército, dando ao Exército chileno o controle sobre a polícia de todo país." (PEREIRA, 2010, p. 93). O que findou por se tornar, juntamente com o arcabouço normativo constituído ainda durante o governo dos civis, em um dos grandes legados para a política repressiva da ditadura militar vindoura. Criou, em 1930, a Força Aérea chilena. Tendo seu governo perdurado até 1931, quando, por pressão da oposição e falta de sustentação política, Ibáñez renunciou ao mandato.

Na sequência, entre 1932 a 1973, o Chile retornou à tradição majoritária de governos civis, os quais foram responsáveis por estabelecer uma submissão temporária das forças armadas ao Poder Executivo, assim como por permitir uma ascensão gradual dos partidos políticos de esquerda, com destaque para o Partido Comunista e o Partido Socialista. (PEREIRA, 2010, p. 80; ROLLEMBERG; QUADRAT, 2010, p. 529). 
A despeito da prevalência dos governos civis, o que se verificou no Chile, após o governo de Ibáñez, foi um processo progressivo de tensionamento - e ruptura - entre os militares e os civis vinculados à esquerda, aliado ao esfacelamento do binômio ideário democrático e observância legal que dantes era tão caro à corporação militar. Tal perfilhamento não se concebeu, nem foi implementado, de maneira isolada. Ao contrário, operou-se dentro das instituições e dos mecanismos democráticos, sobretudo, nas conjecturas e apreciações legislativas levadas a cabo pela oposição no Congresso chileno.

Nesse contexto, merece destaque o arcabouço normativo construído antes do golpe militar de 1973, mais especificamente quando do segundo mandato de Ibáñez (19521958), já caracterizado por inequívocas marcas autoritárias e contributivo para a intervenção direta das forças armadas nas questões civis, o que pode ser exemplificado por meio da Lei no 8.987, datada de 3 de setembro de 1948, conhecida como Ley de Defensa Permanente de la Democracia ou simplesmente Ley maldita, "responsável por colocar na ilegalidade o Partido Comunista, proibir os seus membros de participar de sindicatos, criar zonas para o banimento de supostos subversivos". (PEREIRA, 2010, p.

94). Tal lei, também, cuidou de reprimir o movimento trabalhista urbano e a organização sindical rural. (PEREIRA, 2010, p. 94).

Importante salientar que a Lei $n^{\circ} 8.987 / 48$, perdurou por uma década, quando foi substituída pela Lei $\mathrm{n}^{\mathrm{o}} 12.927$, datada de 6 de agosto de 1958, denominada de Lei da Segurança Estatal. Por semelhante modo, esta norma também gozava de notas autoritárias, especialmente ao garantir, entre outros expedientes, “[...] uma definição muito ampla e muito pouco liberal dos crimes contra o Estado" (PEREIRA, 2010, p. 95), favorecendo, assim, a sua aplicação contra os opositores políticos do governo de Jorge Alessandri e os do porvir ditatorial.

A escalada para o autoritarismo alcançou um novo patamar normativo no ano de 1960, quando, o Poder Executivo garantiu o direito de decretar estado de exceção sem que, para tanto, houvesse uma prévia autorização do Congresso, medida que facilitou a repressão às greves nas minas de cobre (PEREIRA, 2010, p. 95) e a intervenção dos militares nos conflitos civis. (SADER, 1984, p. 12). Em contrapartida, registra-se uma 
significativa ascensão das esquerdas, agora, no Legislativo, já na eleição de 1961. (ROLLEMBERG; QUADRAT, 2010, p. 528)

Na sequência, o governo do presidente Eduardo Frei Montalva, (1964-1970), pautado no lema "Revolución en Libertad", implementou algumas reformas de cunho social, entre as quais, merecem registro a deflagração da reforma educacional no Chile (ROLLEMBERG; QUADRAT, 2010, p. 531) e a expropriação de latifúndios. (GALEANO, 2014, p. 176). Por outra banda, em 1966, seu governo foi responsável por expedir um novo decreto de caráter repressivo, que "autorizava o Exército a entrar na cidade de El Salvador, o que de fato ocorreu, para pôr fim às reivindicações dos trabalhadores. O Exército e os carabineros acabaram por matar sete pessoas e ferir 35, segundo as cifras oficiais”. (PEREIRA, 2010, p. 95).

No ano de 1970, lastreado por uma ampla frente partidária e defendendo um programa de governo progressista, o candidato da Unidade Popular (UP), Salvador Allende Gossens, após três tentativas infrutíferas, foi eleito presidente do Chile com uma pequena margem em relação à frente conservadora representada por Jorge Alessandri. ${ }^{4}$

As polarizações políticas originadas nas urnas foram recrudescidas durante todo o mandato de Allende, situação muito assemelhada à vivenciada por João Goulart, no Brasil (LOPES; CHEHAB, 2014, p.201), que também foi obrigado a lidar com os imbróglios potencializados pelo Judiciário, pelo Legislativo, pelos militares e por representantes da direita chilena.

Aos primeiros, portanto, ao Poder Judiciário, confere-se a responsabilidade pelas disputas em torno de supostos descumprimentos de mandados judiciais pelo Poder Executivo, o que desfavoreceu as relações de Allende com o Judiciário, ao ponto da Corte Suprema publicar uma nota de repúdio ao presidente. Por sua vez, ao Poder Legislativo coube o encargo de obstaculizar normativamente o governo de Allende, expediente que se fez emblemático por meio da aprovação da Lei nº 17.798, de 21 de

\footnotetext{
${ }^{4}$ Nesse sentido, indica Moraes (2001, p. 237): “[...] a vitória eleitoral da Unidade Popular, no Chile, foi duplamente limitada: Salvador Allende obteve, apenas, em 1970, um terço - 36\% - dos votos, enquanto a oposição burguesa conservou a maioria do Parlamento".
} 
se fez emblemático por meio da aprovação da Lei $n^{\circ} 17.798$, de 21 de outubro de 1972, responsável pelo controle de armas, matéria que fora demandada pelos militares e, a partir de sua vigência, tornou-se garantidora, em caráter amplo, do monitoramento e da repressão de grupos paramilitares pelas forças armadas. (PEREIRA, 2010, p. 96). Os militares também desempenharam o papel de manipuladores das massas em oposição a Allende, provocando, juntamente com os seus aliados civis, inclusive nações estrangeiras, como o Brasil $^{5}$, um temor desarrazoado na população acerca de um possível golpe comunista a ser deflagrado pelo presidente, conjugado a uma repressão violenta contra quaisquer manifestações políticas ${ }^{6}$. (MUÑOZ, 2010, p. 43) Ainda, merecem destaque as desordens sociais deliberadamente provocadas por manifestantes isolados, movimentos aristocráticos de direita e pelo Patria y Liberdad, ${ }^{7}$ que colaboraram para o sentimento de medo e insegurança da população chilena. (MORAES, 2001, p. 241).

A despeito de todo o movimento que lhe era adverso, Allende foi ganhando respaldo das classes populares, ao ampliar o acesso à educação secundária e universitária (QUADRAT, 2010, p. 531), promover medidas que garantiram a redução da mortalidade infantil (GALEANO, 2014, p. 354), estimular a participação popular por meio de plebiscitos (MENDES, 2013, p.6), firmar políticas para uma progressão do poder de compra, por meio do aumento do salário, e para efetivação de uma alimentação adequada, especialmente para as crianças. (MORAES, 2001, p. 240).

As críticas persistiam no que se referia às propostas de reforma agrária e de nacionalização das minas de cobre (GALEANO, 2014, p. 176; 194) e dos bancos (PEREIRA, 2010, p. 154), insatisfações representadas, principalmente, pela histórica

\footnotetext{
${ }^{5}$ Acerca das implicações do Brasil no golpe chileno, Pereira (2010, p. 149-150) registra que: "O embaixador brasileiro no Chile à época do golpe de 1973, Antônio da Câmara Couto (sic), mantinha relações tão estreitas com o novo regime militar que foi chamado por alguns de 'o quinto membro da junta'. O embaixador coordenou a perseguição aos exilados brasileiros vivendo no Chile e, sob sua direção, a Embaixada brasileira tornou-se uma base de operações para a conspiração contra o governo Allende."

${ }^{6}$ Fato também ocorrido no Brasil, por meio das manifestações promovidas pelo Instituto de Pesquisas e

Estudos Sociais (IPES) e pelo Instituto Brasileiro de Ação Democrática (IBAD). (MORAES, 2001, p. 111). Devendo ser esclarecido sobre esses últimos, quais sejam IPES e IBAD, que, subjacentes aos títulos de "institutos", os mesmos já discutiam, desde 1961, estratégias para a tomada do poder e para, consequentemente, ditar os rumos da economia, em específico, para permitir a abertura de mercados, a remessa de divisas ao estrangeiro e o aumento de investimentos do Estado para a iniciativa privada. (BRUM, 1999, p. 293-294).

${ }^{7}$ Movimento paramilitar chileno de ultradireita que se aliou às forças militares para a derrubada do então presidente Salvador Allende. Também conhecido como Frente Nacionalista Patria y Libertad.
} 
oligarquia chilena e pelo governo norte-americano, que, sentindo-se ameaçados, fortaleceram sua estratégia ofensiva contra o governo de Allende. ${ }^{8}$

Nesses termos, pode-se atribuir à intensificação desses conflitos, por meio de embates políticos e embargos econômicos, a deflagração do golpe militar, que uniu as três forças armadas, destacadamente o Exército chileno, em um golpe contra o Presidente Salvador Allende, datado de 11 de setembro de $1973 .{ }^{9}$

\section{A DITADURA CHILENA}

Com a derrocada e morte de Salvador Allende, a junta militar responsável pelo golpe decretou um estado sítio; estabeleceu o toque de recolher, providenciou julgamentos e execuções sumárias e fechou o Congresso Nacional chileno. (PEREIRA, 2010, p. 159). Imediatamente após o golpe, também, nomeou Augusto Pinochet Ugarte como Presidente da Junta de Governo, posição na qual permaneceu até junho de 1974. Posteriormente, foi indicado como Chefe Supremo da Nação, cargo que exerceu até 17 de dezembro de 1974. E na sequência, assumiu a Presidência da República do Chile de 17 de dezembro de 1974 até 11 de março de 1981.

Registra-se, por oportuno, que diferentemente da ditadura brasileira, que teve uma intervenção direta e uma implementação ampla urdida por quadros políticos civis, o regime chileno foi formado - quase em sua integralidade - por militares, que já gozavam de certa autonomia, ainda durante o governo Allende, para a manutenção da ordem. (MORAES, 2001, p. 233). Em outras palavras, embora tendo contado com o auxílio político e financeiro dos civis para a deflagração do golpe contra Allende, o governo ali formado, arregimentouse e pautou-se pelos ditames da junta militar. Em seu comando, fez constar, apenas, dois ministros civis e subjugou grande parte da jurisdição civil aos tribunais militares (PEREIRA, 2010, p. 157).

${ }^{8}$ Nesse sentido, destacam-se os relatos de Moraes (2001, p.231-233), assim como de Gaspari (2002, p. 302303; p. 371-372).

${ }^{9}$ De acordo com Moraes (2001, p. 227), convém registrar que em 29 de junho de 1973 houve a primeira tentativa de golpe contra o governo Allende, que restou conhecida como "tancazo". 
$\mathrm{Na}$ fase mais violenta da repressão, a ditadura militar chilena valeu-se de prisões e execuções sumárias contra opositores específicos. ${ }^{10}$ Nesse contexto, merece destaque a utilização do Estádio Nacional, durante os primeiros dias que sucederam ao golpe militar, como centro de interrogatórios, tortura e fuzilamentos (BRASIL, 2014, p. 239), que contou, inclusive, com o auxílio de uma equipe de militares e policiais brasileiros para o cometimento de graves violações de direitos humanos, como relatou o Embaixador Adolpho Benevides à Comissão Nacional da Verdade. (BRASIL, 2014, p. 244). ${ }^{11}$

Outro expediente que demonstra a magnitude da violência praticada pela ditadura chilena, ainda nos seus primeiros meses, diz respeito à Caravana da Morte, levada a efeito durante o mês de outubro de 1973 e liderada pelo general Sérgio Arellano Stark, quem, com a anuência do alto comando das forças armadas, inclusive do próprio Pinochet (MAÑLICH R., 2010, p. 56), circulou pelas províncias do norte chileno executando sumariamente cerca de 75 prisioneiros já sentenciados (PEREIRA, 2010, p. 160-161).

Também colaborou para a escalada de violência no Chile, a Dirección de Inteligencia Nacional (DINA), criada no dia 5 de janeiro de 1974, com o auxílio direto da ditadura brasileira $^{12}$ (KRISCHKE, 2009, p. 233), mas que somente passou a gozar de publicidade com o advento do Decreto-Lei $n^{\circ}$ 521, datado de 14 de junho de 1974. (MENDES, 2013, p.9). Coordenada por Manuel Contreras Sepúlveda, tinha por escopo principal desenvolver atividades referentes à "polícia política e serviço de inteligência,

${ }^{10} \mathrm{Um}$ dos grupos de opositores do regime ditatorial que mais sofreu com os desaparecimentos e assassinatos provocados pela repressão chilena foi o Movimiento de la Izquierda Revolucionaria (MIR), grupo de tendência socialista revolucionário. De acordo com Hernán Vidal (2014, p.6) "En su Informe Rettig (1991) la Comisión de Verdad y Reconciliación indica que durante la dictadura militar el MIR tuvo 384 bajas entre muertos en enfrentamientos, ejecutados y desaparecidos, un 16,9\% de la militancia durante el período, alrededor de 2.210 militantes según este estimado. [...] En una investigación del 2009 José Calderón López hace un recuento más devastador pues un mínimo de 398 miristas habrían sido muertos sólo entre 1973-1975 (Calderón 2009, 212-264). En la actualidad con frecuencia se menciona que fue alrededor de 800 el número total de muertos y desaparecidos del MIR a manos de los servicios de seguridad militar."

${ }^{11}$ Embora não haja precisão, estima-se que 4.400 pessoas foram presas no Estádio Nacional do Chile, das quais, aproximadamente, 108 eram brasileiras. (BRASIL, 2014, p. 238-239).

${ }^{12}$ De acordo com Krischke (2009, p. 237) e com Pereira (2010, p. 150), o Brasil colaborou também no assessoramento e nas técnicas de tortura, assim como na cessão de militares e policiais brasileiros para os interrogatórios de opositores do regime militar chileno ocorridos no Estádio Nacional. Por semelhante modo, de acordo com Gaspari (2014, p. 382), mencionando relato do próprio Contreras, oficiais chilenos eram enviados para treinamento em um centro antiguerrilheiro brasileiro, localizado em Manaus, AM. 
controlada de modo direto pelo Presidente Pinochet, tirou a repressão cotidiana das mãos dos militares.” (PEREIRA, 2010, p. 60).

A DINA ${ }^{13}$ envolveu-se em assassinatos de críticos da ditadura chilena no exterior, a exemplo de Carlos Prats, comandante das forças armadas durante o governo Allende, morto no seu exílio em Buenos Aires, juntamente com sua esposa, em setembro de 1974; e de Orlando Letelier del Solar, ministro das Relações Exteriores do governo Allende, morto em Washington-DC, juntamente com sua secretaria, registre-se: uma cidadã americana, em setembro de 1976. (BRASIL, 2014, p. 222).

Em razão da repercussão em torno da participação da DINA nessas mortes, esta findou por ser substituída pela Central Nacional de Información (CNI), nos termos do Decreto-Lei no 1.873, de 13 de agosto de 1977, que prosseguiu em funcionamento até 1990. (MENDES, 2013, p. 9).

Por semelhante modo, o Chile se destacou pela ampla jurisdição dos seus tribunais militares de tempo de guerra nos supostos crimes praticados por civis, até o final de 1978. Estima-se que esses tribunais tenham julgado cerca de 6.000 pessoas nos primeiros cinco anos do regime, das quais, aproximadamente, 200 foram sentenciadas à pena de morte.

Outro dado relevante sobre esses tribunais diz respeito ao seu baixo índice de absolvição, ${ }^{14}$ em cerca de, apenas, $12,42 \%$ dos casos ali processados. (PEREIRA, 2010, p. 166). Convém registrar, também, que tais expedientes estavam em plena consonância com Suprema Corte, que de quase 9000 habeas corpus ali impetrados, somente concederam a ordem em 30 casos. (PEREIRA, 2010, p. 173).

Ainda, não pode ser olvidado que a maioria dos julgamentos transcorria em dias; não costumavam contar com a participação de qualquer juiz civil e as acusações mais comuns referiam-se à violação da Lei de Controle de Armas e da Lei de Segurança do

\footnotetext{
${ }^{13}$ Estima-se que a DINA tenha contado com, aproximadamente, 60.000 agentes e tenha responsabilidade - seja direta ou indireta - em parte significativa dos 38.000 torturados durante o regime ditatorial chileno. (TORTURADOR..., 2015, online).

${ }^{14}$ Convém sublinhar que, de acordo com Pereira (2010, p. 131), tal índice é quase quatro vezes menor que a média observada no Nordeste, qual seja, 44,74\%, região que registrou a menor taxa de absolvição nos julgamentos por crimes contra a segurança nacional durante a ditadura civil-militar brasileira.
} 
Estado - ambas anteriores à instalação da ditadura militar chilena. (PEREIRA, 2010, p. 59).

O Chile se notabilizou, igualmente, como uma das nações idealizadoras ${ }^{15}$ da Operação Condor (também conhecida como Plano Condor), ${ }^{16}$ que se constituiu em uma "rede que ligava os serviços de inteligência do Chile, Paraguai, Uruguai, Argentina, Brasil e Estados Unidos, trocando informações e coordenando sequestros e assassinatos em toda a região". (PEREIRA, 2010, p. 60). Mais que isto, a Operação Condor, de acordo com Gaspari (2014, p. 381): "Na sua face clandestina, destinava-se a formar uma versão internacional do Esquadrão da Morte."

Nos idos de 1975, o Estado chileno sediou a reunião, onde se fizeram presentes Argentina, Bolívia, Brasil, Paraguai e Uruguai (BRASIL, 2014, p.221), na qual fora dado início as atividades da Operação Condor e apresentadas as seguintes proposições: “[...] archivo centralizado de antecedentes de personas, organizaciones y otras actividades conectadas directa o indirectamente con la subversión. En líneas generales, dijo, algo similar lo que tiene INTERPOL en Paris pero dedicado a la subversión." (ALMADA, 2013, p. 240). Para tanto, o Chile defendia a utilização de medidas tais como: “o desaparecimento dos oponentes ao regime; a tortura sistemática; a entronização ou controle e manipulação dos meios de comunicação; o exílio forçado de grupos sociais e políticos.” (ALMADA, 2009, p. 219).

O Relatório final da Comissão Nacional da Verdade brasileira (BRASIL, 2014, p. 222), ao considerar a complexidade e a rede de alcance da Operação Condor, apontou como sendo suas principais notas caracterizadoras: “operação de natureza multinacional; ação transfronteiriça dirigida a pessoas exiladas no estrangeiro; estrutura paraestatal de

\footnotetext{
15 Em sentido mais amplo, Deborah Estri Motta (2004, p. 251) afirma que: “A coordenação da Operação cabia aos órgãos de inteligência chilenos, que serviam como uma espécie de 'base de informações', estabelecendo contato direto com a CIA e repassando suas diretrizes aos demais países." Por semelhante modo, Gaspari (2004, p. 381) relata que Pinochet pretendeu criar, no Chile, um Escritório de Coordenação e Segurança da Operação Condor. Já Goméz (2008, p. 103), menciona a importância de Manuel Contreras, chefe da DINA, para a idealização e ulterior deflagração da Operação Condor, citando como provas, para tanto, aqueles conhecidos como "Arquivos do Terror" provenientes da ditadura paraguaia, que apresentam, em detalhes, tais articulações.

16 O Relatório final da Comissão Nacional da Verdade (BRASIL, 2014, p. 220) também incluiu a Bolívia no rol de países participantes da Operação Condor.
} 
funcionamento; seleção precisa de dissidentes; utilização de grupos extremistas, como 'sindicatos do crime' e 'esquadrões da morte'; e uso de tecnologia avançada para acesso a um banco de dados comum."

Finalmente, deve ser sublinhado que a Operação Condor contou, também, com o apoio massivo dos Estados Unidos da América (EUA), especialmente no que tange ao seu aparato logístico e tecnológico. (BRASIL, 2014, p. 222). Em números, estima-se que tal Operação tenha vitimado - direta ou indiretamente - cerca de 10.000 pessoas em toda a América Latina. (ALMADA, 2013, p. 243).

\section{TRANSIÇÃO PARA A DEMOCRACIA NO CHILE}

O processo transitório chileno iniciou-se em 19 de abril de 1978, portanto, ainda durante o governo militar, quando foi promulgada a anistia, que teve por objetivo isentar os responsáveis pelas graves violações de direitos humanos cometidas entre 11 de setembro de 1973 e abril de 1978. (CATELA, 2000, p. 302).

No ano de 1980, uma nova constituição foi promulgada no Chile, cujas alterações permitiram, entre outros benefícios aos militares, a ampliação do mandato presidencial de seis para oito anos, (CATELA, 2000, p. 302), prazo que ainda se encontra em vigência. (PEREIRA, 2010, p. 247).

Já em outubro de 1988, foi convocado um plebiscito que, por pequena vantagem em favor da oposição, denegou a prorrogação de mandato à Pinochet. Por via consequente, a junta militar determinou o chamamento de novas eleições presidenciais, que ocorreram em junho de 1989 e foram vencidas, com 55\% dos votos, por Patrício Alwyin Azócar, ${ }^{17}$ candidato da frente ampla de oposição denominada Concertación Democrática. (ARAVENA, 2000, p. 135).

Alwyin tomou posse em 11 de março de 1990 e já no mês seguinte, portanto em abril de 1990, criou, por meio do Decreto $\mathrm{n}^{\circ} 355$, de 25 de abril de 1990, a Comisión Nacional de Verdad y Reconciliación, com o objetivo de examinar as graves violações de

${ }^{17}$ É importante registrar que, “Aylwin havia apoiado o golpe em 1973, tendo, entretanto, se convertido num crítico importante do regime militar e, em particular, da Constituição de 1980." (PEREIRA, 2010, p. 248). 
direitos humanos perpetradas entre 11 de setembro de 1973 e 11 de março de 1990. Seu funcionamento foi delimitado entre 9 maio de 1990 a 9 de fevereiro de 1991, tendo sido presidida pelo ex-senador Raúl Rettig, quem findou por conferir seu nome à Comissão e ao seu posterior Relatório.

Diferentemente dos demais países do Cone Sul, a Comisión Nacional de Verdad y Reconciliación contou com uma participação híbrida de dissidentes e de simpatizantes da ditadura. (GOMÉZ, 2008, 115) Fez, também, uso dos arquivos da Vicaría de la Solidariedad ${ }^{18}$, juntamente com os relatos de familiares de mortos e desaparecidos políticos pela ditadura chilena. (PEREIRA, 2010, p. 249).

O relatório final da Comissão foi entregue ao presidente Aylwin em 8 fevereiro de 1991, quando foram reconhecidos 2.279 desaparecidos, os quais foram considerados mortos. (CATELA, 2000, p. 302). Por outra banda, estima-se que, se somados os mortos e desaparecidos, esse número poderia alcançar entre 3.000-5.000 vitimados. ${ }^{19}$ Já os presos pela ditadura chilena estão em torno de 60.000 pessoas e os exilados, em aproximadamente, 40.000 pessoas. (PEREIRA, 2010, p. 56). Outro dado constrangedor diz respeito ao número de crianças e adolescentes submetidos a graves violações de direitos humanos pela ditadura chilena: estima-se que, pelo menos, 39 deles desapareceram e outros 1.224 foram presos. (NEPOMUCENO, 2015. p. 82).

Por meio dos relatos e documentos analisados pela Comisión, "[...] chegou à conclusão de que $95 \%$ das violações constatadas foram da responsabilidade dos agentes do Estado e só 4\% das organizações armadas de esquerda.” (GOMÉZ, 2008, p. 115), o que demonstra a desproporcionalidade dos atos cometidos pela repressão em face dos resistentes, ratificando, assim, a tese de terrorismo de estado praticado pelos agentes -

\footnotetext{
18 Organização eristã responsável pela defesa da maioria dos presos políticos durante a ditadura chilena, o que garantiu o acesso pelas suas advogadas e pelos seus advogados aos documentos referentes aos julgamentos levados a cabo nos tribunais militares.

19 Já Eric Nepomuceno (2015, p. 82) menciona que: “[...] pelo menos 3.200 chilenos desapareceram durante a ditadura (entre eles 39 menores de idade), e que os presos políticos foram pelo menos 28.459 (1.244 deles eram menores)" O número oficial das Comissões chilenas é de [...] "3.185 desaparecidos, executados ou assassinados de maneira sumária. Individualizaram 28.459 torturados e detectaram 1.132 locais de detenção e tortura, o último deles há pouco tempo, em 2008." (NEPOMUCENO, 2015, p. 96).
} 
direta ou indiretamente - vinculados à ditadura contra uma sociedade que lhe era, em efetivo, refém.

Embora não tenho alcançado a mesma visibilidade do Relatório argentino, distribuído massivamente entre a população, nem a sua efetividade contígua, que permitiu sanções imediatas aos seus agentes repressores, o Relatório Rettig buscou cumprir - mesmo que parcialmente - seu compromisso com a transição, na medida em que o então presidente Alwin pediu perdão à nação em nome do Estado e afirmou da continuidade do processo transitório por meio do e no Judiciário. (CATELA, 2000, p. 302).

Em 1991, o Estado chileno foi condenado pela OEA a pagar uma indenização aos parentes de Letelier e de sua secretaria, em razão de atentado levado a cabo pela DINA em Washington - DC, que provocou a morte de ambos, em 1976. (CATELA, 2000, p. 302). E em 1995, Manuel Contreras e Pedro Espinoza foram responsabilizados pessoalmente por tal crime, o que lhes engendrou uma condenação à prisão. (D'ARAÚJO; CASTRO, 2000, p. 327).

Na sequência, foi criada, por meio da Lei $\mathrm{n}^{\circ} 19.123$, datada de 8 de fevereiro de 1992, a Corporación Nacional de Reparación y Reconciliación responsável por garantir novos fundamentos à efetivação da transição para a democracia no Chile, sobretudo, no que tange às vítimas de desaparecimentos e execuções. Em números, “[...] recibió 1.200 denuncias, de las cuales 899 fueron consideradas como casos calificados de violaciones a los derechos humanos, los que sumados a los casos calificados por el Informe de la Comisión Nacional de Verdad y Reconciliación, da un total de 3.195 casos calificados." (CHILE, 2015 online).

No ano de 1998, por meio de um pedido de extradição efetuado pelo juiz espanhol Baltazar Garzón, fundamentado na tese do cometimento de crimes de lesa humanidade pelos agentes da repressão chilena (GOMÉZ, 2008, p.95), o ex-presidente Augusto Pinochet foi preso na Inglaterra, onde se encontrava viajando. (CATELA, 2000, p. 303). 
A prisão de Pinochet pode ser caracterizada como um ponto de inflexão para o processo de transição chileno, na medida em que ele próprio representava uma parte significativa da ditadura chilena, que não fora apenas militar, mas, sobretudo, personificada. (ARAVENA, 2000, p. 147). Destarte, sua prisão traduziu a mensagem de efetivação da derrocada gradual dos efeitos do regime ditatorial e da ingerência militar nos espectros da democracia chilena. Isto não significou, todavia, que a era militar estava concluída, mas, tão somente, que a segregação das forças armadas em relação aos civis e o seu desdém às leis civis estariam progressivamente ganhando novos contornos, nos quais repousa a supremacia democrática.

Tal tese seria, inclusive, ratificada pela criação, em 2003, da Comisión sobre Prisión Política y Tortura, também conhecida como Comisión Valech, em homenagem ao seu presidente Sergio Valech, que complementou o trabalho já implementado por suas similares, especialmente no que concerne à oitiva de cerca de 35.000 vítimas da ditadura chilena, expediente que corroborou para o julgamento e a condenação, em primeira instância, de Pinochet. Essa Comissão funcionou, inicialmente, até 2005, e depois retornou à coleta de depoimentos entre 2010 e 2011.

Se o processo transitório chileno foi profícuo para com o pilar da verdade, ainda apresenta-se como deveras tímido no que tange à efetivação da justiça. Diz-se isto porque o Judiciário chileno, que apoiou sistematicamente a ditadura (GOMÉZ, 2008, p. 116), mas que não recebeu o mesmo respaldo do regime militar quando do seu término, tem buscado promover uma renovação administrativa em tempos democráticos, entretanto, torna-se limitado pelos entraves normativos patrocinados pelos próprios militares.

Nesse sentido, o Judiciário tem que lidar com um arcabouço normativo ainda imbricado na lógica autoritária, a começar pela atual Constituição chilena, vigente desde 1980, quando da ditadura de Pinochet. Por seu turno, as normas que lhe são decorrentes, em sua maioria, garantem aos militares benesses, como a segregação do comando e da jurisdição civis e a continuidade da vigência de diversos decretos expedidos quando da ditadura. (PEREIRA, 2010, p. 248-249). Para Aravena (2000, p. 129), é justamente este modelo de "democracia protegida", onde subsiste a ingerência dos militares e da sua 
herança normativa, que torna prejudicada a concretização de uma democracia genuína no Chile.

A despeito disto, a partir dos anos 2000, acompanhou-se uma sequência de pedidos de desculpas formais pelas mais diversas instituições, merecendo especial destaque, o pedido de perdão levado a cabo pelo Presidente da Corte Suprema chilena, Rubén Ballesteros, no ano de 2003, em razão "das graves ações e omissões que ocorreram” no Poder Judiciário. Por semelhante modo, deve ser sublinhado o reconhecimento da responsabilidade das Forças Armadas, nos anos de 2003 e 2004, especificamente no que concerne às graves violações de direitos humanos cometidas durante a ditadura militar. (GOMÉZ, 2008, p.122).

Já em 26 de setembro de 2006, a Corte Interamericana de Direitos Humanos, prolatou decisão emblemática ao apreciar o caso Almonacid Arellano y otros vs. Chile, que versava sobre a prisão e o consequente assassinato cometido por carabineros, no dia 16 de setembro de 1973, contra Luis Alfredo Almonacid Arellano, que gozava de 42 anos, era professor e dirigente do Partido Comunista do Chile.

Naquela ocasião, a Corte entendeu que o Decreto $\mathrm{n}^{\circ} 2.191$, publicado em 18 de abril de 1978 pela junta militar chilena, com o condão de promover uma autoanistia aos agentes da repressão, carecia de efeitos jurídicos. Em termos objetivos, considerou que o Decreto $n^{o}$ 2.191/78 descumpria diversos artigos da Convenção Americana de Direitos Humanos, da qual o Chile era signatário, podendo-se citar, em específico, os seus artigos 1.1, 2, 8 e 25 20, sobretudo, por não responsabilizar os assassinos do caso Almonacid Arellano, nem reparar os seus familiares. (ALCALÁ, 2006, p. 374).

\footnotetext{
20 “Artigo $1^{\circ}$ - Obrigação de respeitar os direitos

1. Os Estados-partes nesta Convenção comprometem-se a respeitar os direitos e liberdades nela reconhecidos e a garantir seu livre e pleno exercício a toda pessoa que esteja sujeita à sua jurisdição, sem discriminação alguma, por motivo de raça, cor, sexo, idioma, religião, opiniões políticas ou de qualquer outra natureza, origem nacional ou social, posição econômica, nascimento ou qualquer outra condição social.'

Artigo $2^{\circ}$ - Dever de adotar disposições de direito interno

Se o exercício dos direitos e liberdades mencionados no artigo 1 ainda não estiver garantido por disposições legislativas ou de outra natureza, os Estados-partes comprometem-se a adotar, de acordo com as suas normas constitucionais e com as disposições desta Convenção, as medidas legislativas ou de outra natureza que forem necessárias para tornar efetivos tais direitos e liberdades.
} 
Tal decisão teve efeito irradiador em relação às demais normas de anistia apreciadas pela Corte e elaboradas por países outrora submetidos a ditaduras que buscaram, por meio de decretos e/ou leis, extinguir a responsabilidade dos agentes da repressão para com as graves violações de direitos humanos cometidas. Nesse sentido, pode ser citada como exemplo de irradiação direta da decisão do caso Almonacid, a sentença prolatada, pela Corte, em 24 de novembro de 2010, no caso Gomes Lund e outros vs. Brasil, que versa sobre a Guerrilha do Araguaia, acerca do qual já se fora comentado no corpo do capítulo 2 deste trabalho.

Outro ponto relevante da transição democrática no Chile refere-se à defesa e promoção da memória, que se faz representar pelo Museo de la Memoria e los Derechos

Artigo $8^{\circ}$ - Garantias judiciais

1. Toda pessoa terá o direito de ser ouvida, com as devidas garantias e dentro de um prazo razoável, por um juiz ou Tribunal competente, independente e imparcial, estabelecido anteriormente por lei, na apuração de qualquer acusação penal formulada contra ela, ou na determinação de seus direitos e obrigações de caráter civil, trabalhista, fiscal ou de qualquer outra natureza.

2. Toda pessoa acusada de um delito tem direito a que se presuma sua inocência, enquanto não for legalmente comprovada sua culpa. Durante o processo, toda pessoa tem direito, em plena igualdade, às seguintes garantias mínimas:

a) direito do acusado de ser assistido gratuitamente por um tradutor ou intérprete, caso não compreenda ou não fale a língua do juízo ou tribunal;

b) comunicação prévia e pormenorizada ao acusado da acusação formulada;

c) concessão ao acusado do tempo e dos meios necessários à preparação de sua defesa;

d) direito do acusado de defender-se pessoalmente ou de ser assistido por um defensor de sua escolha e de comunicar-se, livremente e em particular, com seu defensor;

e) direito irrenunciável de ser assistido por um defensor proporcionado pelo Estado, remunerado ou não, segundo a legislação interna, se o acusado não se defender ele próprio, nem nomear defensor dentro do prazo estabelecido pela lei;

f) direito da defesa de inquirir as testemunhas presentes no Tribunal e de obter o comparecimento, como testemunhas ou peritos, de outras pessoas que possam lançar luz sobre os fatos;

g) direito de não ser obrigada a depor contra si mesma, nem a confessar-se culpada; e

h) direito de recorrer da sentença a juiz ou tribunal superior.

3. A confissão do acusado só é válida se feita sem coação de nenhuma natureza.

4. O acusado absolvido por sentença transitada em julgado não poderá ser submetido a novo processo pelos mesmos fatos.

5. O processo penal deve ser público, salvo no que for necessário para preservar os interesses da justiça.

Artigo 25 - Proteção judicial

1. Toda pessoa tem direito a um recurso simples e rápido ou a qualquer outro recurso efetivo, perante os juízes ou tribunais competentes, que a proteja contra atos que violem seus direitos fundamentais reconhecidos pela Constituição, pela lei ou pela presente Convenção, mesmo quando tal violação seja cometida por pessoas que estejam atuando no exercício de suas funções oficiais.

2. Os Estados-partes comprometem-se:

a) a assegurar que a autoridade competente prevista pelo sistema legal do Estado decida sobre os direitos de toda pessoa que interpuser tal recurso;

b) a desenvolver as possibilidades de recurso judicial; $\mathrm{e}$

c) a assegurar o cumprimento, pelas autoridades competentes, de toda decisão em que se tenha considerado procedente o recurso". 
Humanos, construído na capital Santiago e inaugurado em 11 de janeiro de 2010, que traz a lume, por meio de variados relatos das Comissões chilenas, a magnitude das graves violações de direitos humanos cometidas pela ditadura chilena, no intuito de que não se repitam. (NEPOMUCENO, 2015, p. 83).

Por semelhante modo, registra-se que outras iniciativas de defesa e promoção da memória também têm sido implementadas pela própria sociedade civil em prédios onde funcionaram antigos centros de tortura, a exemplo da Villa Grimaldi. ${ }^{2 l}$

Igualmente, de grande valia para fins de defesa da memória foi a recente decisão governamental publicizada em junho de 2015, pelo atual ministro da defesa chileno, José Antonio Gómez, acerca da modificação no regimento interno das forças armadas no que tange ao uso de medalhas por militares, destacando-se a proibição de utilização de qualquer distintivo com referência ao golpe militar de 1973. (DEFENSA..., 2015, online).

Ainda, merece ser explicitado que, em maio de 2015, o Poder Judiciário chileno apreciou um processo de reparação de danos ajuizado em razão do sequestro de Álvaro Modesto Vallejos Villagrán, contra ex-membros da DINA e um membro da ex-Colonia Dignidad, os quais foram, ao final, condenados, nos seguintes termos: “[...] o magistrado concedeu uma indenização de $\$ 300.00 .000$ (trezentos milhões de pesos chilenos) à família da vítima e determinou ao Estado chileno a construção de um museu da memória 'Colonia Dignidad', para homenagear e reparar as vítimas da Villa Baviera". (REDE LATINO-AMERICANA DE JUSTIÇA DE TRANSIÇÃO, 2015, online).

Foi também, por meio de uma decisão judicial, prolatada pela Suprema Corte chilena, na data de 20 de maio de 2015, que o ex-chefe da DINA, Manuel Contreras, cujas condenações já somavam 490 anos de prisão, teve sua pena ampliada em 15 anos, perfazendo, portanto, uma pena integral de 505 anos de prisão, em decorrência dos crimes por ele cometidos durante a ditadura, especialmente no que se refere aos desaparecimentos

${ }^{21}$ Conforme Nepomuceno (2015, p. 86), “[...] por ali passaram uns 4.500 presos políticos entre 1973 e 1977. Cerca de 230 deles integram as listas dos desaparecidos para sempre." 
e assassinatos de opositores políticos do regime militar. (TORTURADOR..., 2015, online), mas que restou morto em 7 de agosto de 2015.

\section{CONCLUSÃO}

Á guisa de conclusão, pode ser afirmado, que a despeito do golpe militar chileno ter sido deflagrado apenas em 11 de setembro de 1973, seu arcabouço político e normativo perfectibilizou-se progressivamente, a partir de 1920, com um processo de rompimento para com a sua tradicional vinculação de respeito à legalidade e às instituições.

Nesse contexto, percebeu-se, também, das similitudes entre o regime ditatorial chileno e o brasileiro, representadas pela resistência das oligarquias em relação a Salvador Allende e o progressivo tensionamento entre os civis vinculados aos movimentos de esquerda e os militares, tal qual o corrido durante o governo de João Goulart; somadas à ode à burocracia tradicionalmente cultivada pelo Chile e pelo Brasil.

Igualmente, verificou-se da vinculação entre ambos os países forjada pela influência do Brasil para a deflagração do golpe militar chileno e para as graves violações de direitos humanos ali cometidas, principalmente, por meio da cessão de militares e de policiais brasileiros para o treinamento e o acompanhamento das sessões de tortura ocorridas no Estádio Nacional, o que favoreceu a prisão, apenas naquele centro clandestino, de cerca de 4.400 pessoas, das quais, aproximadamente, 108 eram brasileiras.

Por semelhante modo, observou-se da importância do arcabouço normativo autoritário chileno, constituído ainda durante os governos civis, com destaque para a Ley de Defensa Permanente de la Democracia e para a Lei da Segurança Nacional, que restaram fundamentais para a intervenção repressiva das forças armadas em 1973.

Ainda, pontuou-se da relevância do papel desempenhado pela ditadura chilena, notadamente por meio do então chefe da DINA, Manuel Contreras, para o funcionamento da Operação Condor, iniciada em 1975, que tinha por objetivo promover, juntamente com Uruguai, Paraguai, Argentina, Brasil e Bolívia, adicionado ao apoio logístico dos EUA, a detenção, o desaparecimento, a tortura, a perseguição e a morte de opositores desses regimes de exceções. 
Por derradeiro, averiguou-se que a transição para a democracia no Chile foi marcada, sobretudo, pela instalação de três sucessivas comissões com o fito de apurar as graves violações de direitos humanos cometidas durante aquela ditadura militar; pela intervenção internacional, a exemplo do pedido de extradição e consequente prisão contra Augusto Pinochet; assim como por reiterados pedidos de desculpas institucionais protagonizados pelo Poder Executivo, pelo Poder Judiciário e, mais recentemente, pelas Forças Armadas chilenas.

\section{REFERÊNCIAS}

ALCALÁ, Humberto Nogueira. Los desafíos de la sentencia de la Corte Interamericana en el caso Almonacid Arellano. IusetPraxis (online), v. 12, n. 2, p. 363- 384, 2006.

ALMADA, Martin. Operação Condor: conspiração contra a sociedade do conhecimento. In: SILVA, Haike R. Kleber da (Org.). A luta pela anistia. São Paulo: UNESP, 2009.p.217-230.

. Operación Condor: conspiración contra la sociedad del conocimiento em America Latina. In: LOPES, Ana Maria D’Ávila; MAUÉS, Antônio Moreira (Org.). A eficácia nacional e internacional dos direitos humanos. Rio de Janeiro: Lumen Juris, 2013. p.225-247.

ALMEIDA, Agassiz. A ditadura dos generais: Estado militar na América Latina - O calvário da prisão. Rio de Janeiro: Bertrand Brasil, 2007.

ARAVENA, Francisco Rojas. A detenção do general Pinochet e as relações civismilitares. In: D'ARAÚJO, Maria Celina; CASTRO, Celso (Org.). Democracia e forças armadas no Cone Sul. Rio de Janeiro: FGV, 2000. p. 125-157.

BRASIL. Comissão Nacional da Verdade. Relatório final da CNV. Brasília: CNV, 2014.

BRUM, Argemiro J. O desenvolvimento econômico brasileiro. 20 ed. Petrópolis: Vozes, 1999.

CARVALHO, José Murilo de. A construção da ordem: a elite política imperial. Rio de Janeiro: Civilização brasileira, 2003.

CATELA, Ludmila da Silva. Em nome da pacificação nacional: anistias, pontos finais e indultos no Cone Sul. In: D’ARAÚJO, Maria Celina; CASTRO, Celso (Org.).

Democracia e Forças Armadas no Cone Sul. Rio de Janeiro: FGV, 2000. p.293-313. 
CHILE. Gobierno de Chile. Programa de Derechos Humanos. Disponível em: <http://www.ddhh.gov.cl/informes_cnrr.html>. Acesso em: 10 jun. 2015.

D’ARAÚJO, Maria Celina; CASTRO, Celso (Org.). Democracia e Forças Armadas no Cone Sul. Rio de Janeiro: FGV, 2000.

DEFENSA anuncia prohibicion de medallas alusivas al golpe militar de 1973. Diário La Nación, 12 jun. 2015. Disponível em: < http://www.lanacion.cl/noticias/pais/defensa/defensa-anuncia-prohibicion-de-medallasalusivas-al-golpe-militar-de-1973/2015-06-12/131905.html>. Acesso em: 20 jun. 2015.

GALEANO, Eduardo. As veias abertas da América Latina. Trad. Sergio Faraco. Porto Alegre: L\&PM, 2014.

GASPARI, Elio. As ilusões armadas: a ditadura envergonhada. 2 ed. Rio de Janeiro: Intrínseca, 2014.

. A ditadura escancarada. Companhia das Letras: São Paulo, 2002.

GOMÉZ, José Maria. Globalização dos direitos humanos, legado das ditaduras militares no Cone Sul latino-americano e justiça transicional. Direito, Estado e Sociedade, Rio de Janeiro, n. 33, p. 85-130, jul./dez. 2008.

KRISCHKE, Jair. O Brasil inspirou a Operação Condor. In: SILVA, Haike R. Kleber da (Org.). A luta pela anistia. São Paulo: UNESP, 2009. p.233-253

LOPES, Ana Maria D’Ávila; CHEHAB, Isabelle Maria Campos Vasconcelos. Análise crítica sobre crescimento econômico e desenvolvimento humano do Nordeste brasileiro durante a ditadura civil-militar. In: POMPEU, Gina Vidal Marcílio (Coord.). Direito e Economia I. Florianópolis: CONPEDI, 2014. p.194-213.

MAÑALICH, R. Juan Pablo. A anistia: o terror e a graça - aporias da justiça transicional no Chile pós-ditatorial. Revista Anistia Política e Justiça de Transição, Brasília, n.4, p.32-53, jul./dez.2010.

MENDES, Clécio Ferreira. Ideologia e poder no Chile: ADINA e a repressão na ditadura do general Augusto Pinochet. In: SIMPÓSIO NACIONAL DE HISTÓRIA, XXVII 2013, Natal. Anais eletrônicos. Disponível em: $<$ http://www.snh2013.anpuh.org/resources/anais/27/1371325378_ARQUIVO_IDEOLOGIAEPODERN ADITADURACHILENAANPUH.pdf $>$. Acesso em: 21 maio 2015.

MORAES, João Quartim. Liberalismo e ditadura no Cone Sul. Campinas: UNICAMP, 2001.

MOTTA, Deborah Estri. A repressão extranacional na ditadura militar brasileira: a vigilância do DEOPS paulista sobre o Chile (1970-73). Projeto História, São Paulo, n. 29, t. 1, p. 251-256, dez. 2004. 
MUÑOZ, Heraldo. A sombra do ditador: memórias políticas do Chile sob Pinochet. Rio de Janeiro: Zahar, 2010.

NEPOMUCENO, Eric. A memória de todos nós. Rio de Janeiro: Record, 2015.

O’DONNELL, Guillermo. Reflexões sobre os estados burocráticos-autoritários. Trad. Cláudia Schilling. São Paulo: Vértice, 1987.

ORGANIZAÇÃO DOS ESTADOS AMERICANOS - OEA. Convenção Americana dos Direitos Humanos. Disponível em: <http://www.oas.org/juridico/spanish/tratados/b32.html>. Acesso em: 12 jan. 2014.

PASCUAL, Alejandra Leonor. Terrorismo de Estado: a Argentina de 1976 a 1983. Brasília: Universidade de Brasília, 2004.

PEREIRA, Anthony W. Ditadura e repressão: o autoritarismo e o estado de direito no Brasil, no Chile e na Argentina. Trad. Patrícia de Queiroz Carvalho Zimbres. São Paulo Paz e Terra, 2010.

QUADRAT, Samantha Viz. A oposição juvenil à Unidade Popular. In: ROLLEMBERG, Denise; QUADRAT, Samantha Viz. A construção social dos regimes autoritários: legitimidade, consenso e consentimento no século XX - Brasil e América Latina. Rio de Janeiro: Civilização brasileira, 2010.

REDE LATINO-AMERICANA DE JUSTIÇA DE TRANSIÇÃO. Disponível em: $<<$ http://www.rlajt.com/noticia/141/justi\%C3\%A7a-chilena-condena-ex-integrantes-dadina-e-da-ex-colonia-dignidad-e-ordena-a-constru\%C3\%A7\%C3\%A3o-de-museu-demem\%C3\%B3ria.html>. Acesso em: 13 jun. 2015.

ROLLEMBERG, Denise; QUADRAT, Samantha Viz. A construção social dos regimes autoritários: legitimidade, consenso e consentimento no século XX - Brasil e América Latina. Rio de Janeiro: Civilização brasileira, 2010.

SADER, Emir. Democracia e ditadura no Chile. São Paulo: Brasiliense, 1984.

TORTURADOR da ditadura acumula pena de 505 anos. O Povo Online, Fortaleza, 21 maio 2015.

Disponível em:

$<$ http://www.opovo.com.br/app/opovo/mundo/2015/05/21/noticiasjomalmundo,3441160/torturador-daditadura-acumula-pena-de-505-anos.shtml>. Acesso em: 22 maio 2015.

VIDAL, Hernán. EI movimiento de la Izquierda Revolucionaria (MIR) de Chile en la Justicia Transicional.Columbus: Alternativas, 2014. 